\title{
The 24 August 2016 Amatrice earth- quake: macroseismic survey in the damage area and EMS intensity assessment
}

\author{
QUEST W.G.: RAFFAELE AZZARO*, ANDREA TERTULLIANI, FILIPPO BERNARDINI, ROMANO \\ CAMASSI, SERGIO DEL MESE, EMANUEla ERCOLANI, LAURA GRAZIANI, MARIO LOCATI, \\ Alessandra MARAmai, Vera Pessina, ANTONio Rossi, ANdrea Rovida, PaOla Albini, \\ LUCA ARCORACI, MiCHELE BERARDI, CHRISTIAN BIGNAMI, BEATRIZ BRIZUELA, CORRADO \\ Castellano, Viviana Castelli, SALVATORE D' AMico, Vera D' AMico, ANTONIO \\ FODARELLA, ILARIA LESCHIUTTA, ALESSANDRO PISCINI, MANUELA SBARRA \\ *raffaele.azzaro@ingv.it
}

Istituto Nazionale di Geofisica e Vulcanologia, Italy

\begin{abstract}
The 24 August 2016 earthquake very heavily struck the central sector of the Apennines among the Lazio,Umbria, Marche and Abruzzi regions, devastating the town of Amatrice, the nearby villages and other localities along the Tronto valley. In this paper we present the results of the macroseismic field survey carried out using the European Macroseismic Scale (EMS) to take the heterogeneity of the building stock into account. We focused on the epicentral area, where geological conditions may also have contributed to the severity of damage. On the whole, we investigated 143 localities; the maximum intensity 10 EMS has been estimated for Amatrice, Pescara del Tronto and some villages in between. The severely damaged area (8-9 EMS) covers a strip trending broadly N-S and extending $15 \mathrm{~km}$ in length and $5 \mathrm{~km}$ in width; minor damage occurred over an area up to $35 \mathrm{~km}$ northward from the epicenter.
\end{abstract}

\section{INTRODUCTION}

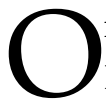
August 24, 2016, 01:36 GMT, central Italy was hit by a $M_{w} 6.0$ earthquake that caused major destruction and 299 fatalities over the central sector of the Apennines among the Lazio, Umbria, Marche and Abruzzi regions. This earthquake was the strongest event of the related seismic sequence, with more than 11,500 events recorded until the end of September. Among the aftershocks, another earthquake exceeded magnitude 5.0 (the same day, at 02:33 GMT, with $\mathrm{M}_{\mathrm{w}} 5.4$ ), and some fifteen had local magnitude larger than 4.0 (INGV working group on the Amatrice earthquake, 2016). Seismological data acquired by the INGV seismic network locate the epicentre of the $\mathrm{M}_{\mathrm{w}} 6.0$ earthquake near the village of Accumoli (province of Rieti), and show an aftershocks distribution along a NWSE trend extending for approximately $40 \mathrm{~km}$. This area partially fills the gap between the 
1997-98 Umbria-Marche (to the north) and 2009 L'Aquila (to the south) seismic sequences. The damage area includes the Umbria and Marche regions as well, with the provinces of Rieti, Perugia, Ascoli Piceno and L'Aquila.

According to the earthquake catalogue CPTI15 (Rovida et al., 2016) the first relevant known event in this area occurred in 1627 (epicentral intensity $\mathrm{I}_{0}$ 7-8 MCS, $\mathrm{M}_{\mathrm{w}}$ 5.3), but information on its effects is scarce being limited to Accumoli. The largest known earthquake destroyed Amatrice and surroundings in 1639 (Io 9-10 MCS, Mw 6.2), with a seismic scenario not unlike the present event.

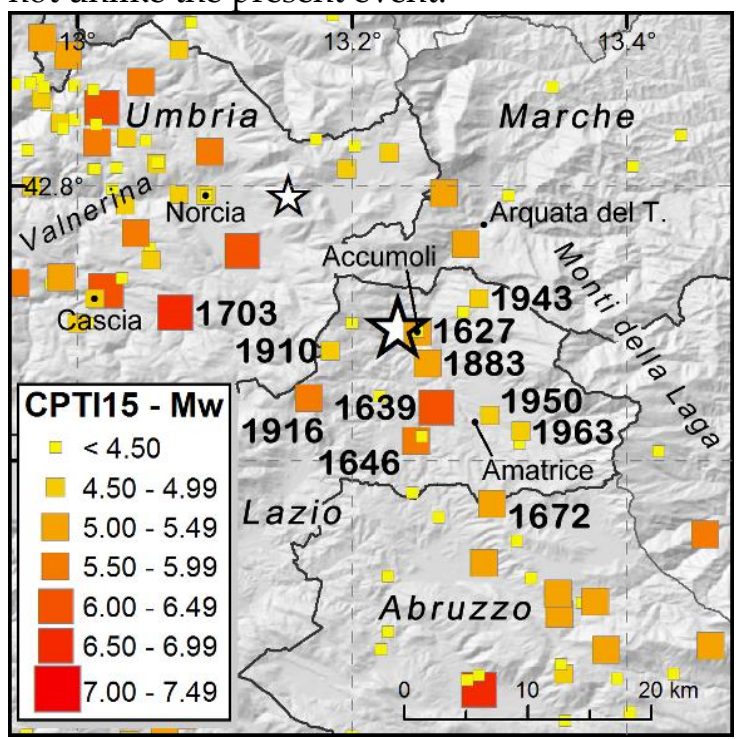

Figure 1: Historical seismicity in the central sector of Apennines from 1000 to 2014 (data from Rovida et al., 2016). The 24 August 2016 mainshock and the $M_{w} 5.4$ aftershock (02:33 GMT) are indicated by white stars.

Other local events affected Monti della Laga in 1646 ( $\mathrm{I}_{0} 9 \mathrm{MCS}, \mathrm{M}_{\mathrm{w}} 5.9$ ) and again Amatrice in 1672 (Io 7-8 MCS, Mw 5.3). Apart from the 1703 seismic sequence (I $\operatorname{mox}_{\max } 11$ MCS, $\mathrm{M}_{\mathrm{w}}$ 6.9) that heavily struck the nearby Valnerina, there are no earthquakes listed in the catalogue till the late 1800s, when the Accumoli-Amatrice area was repeatedly hit by some minor events (1883, Io 7 MCS, Mw 5.1; 1910, In 5-6 MCS, Mw 4.6; 1916, I0 8, Mw 5.5; 1943, I0 6-7, $\mathrm{M}_{\mathrm{w}}$ 4.9; 1950, In 4-5 MCS, $\mathrm{M}_{\mathrm{w}} 4.7$ and 1963, In 7 MCS, $\left.\mathrm{M}_{\mathrm{w}} 4.7\right)$. This paper does not include the macroseismic effects related to the later events of 26 and 30 October, with $\mathrm{M}_{\mathrm{w}} 5.9$ and 6.5 respectively, which occurred in the same area and aggravated the damage scenario described here.

\section{FEATURES OF BUILDINGS AND THEIR VULNERABILITY}

Compared with the Mercalli-Cancani-Sieberg (MCS) scale, the use of the European Macroseismic Scale (EMS, Grünthal, 1998) allows a more coherent interpretation of the damage scenario in the case of settlements made up of very different building typologies. However, its use requires a more detailed consideration of the type of structure and a specific evaluation of the vulnerability. The EMS classifies buildings into 6 classes of decreasing vulnerability, from A to E. Most of the damaged localities consist of historic centres with numerous small hamlets located on the top of the hills or ridges of the Apennines. The traditional buildings have one or more basement levels with barrel vaults, partially above the ground because of the steepness of the terrain, while the upper levels have wooden slabs and roofs. The construction material, of local origin, mainly consists of stones of extremely irregular size, generally rounded or only crudely squared off, assembled incoherently and often without mortar (Fig. 2).

The most common vertical structures are made up of double layer walls, unconnected, with stone faces and rubble masonry fill. This type of structure is classified among the most vulnerable (class A). Both structural aggregates 
and isolated buildings show signs of modifications over time: elevations, openings in the walls, insertion of the terraces at slab level, use of heterogeneous materials other than the original kinds (concrete blocks, bricks) have com-

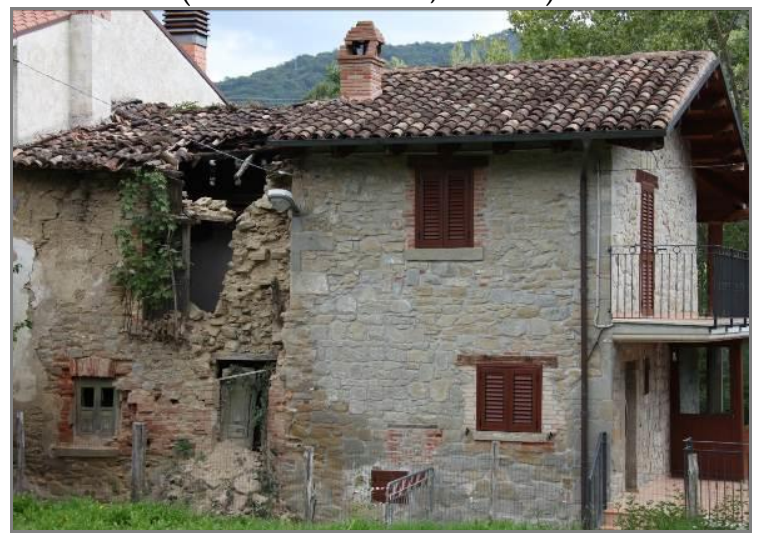

Figure 2: Pascellata (Valle Castellana): masonry building with walls faced with stone and rubble masonry fill. The part in bad state of maintenance compromises the rest of the building.

(laterocemento), without adequate reinforcement of the old vertical walls and proper connections between walls and floors. (Fig. 3). Usually, retrofitting decreased the vulnerability of the buildings (from class A to class B), but in many cases these modifications have compromised the integrity of the entire structure. Many houses were used only as vacation homes or are partially abandoned because of depopulation in the last fifty years. In these cases, the lack of a good state of maintenance has increased their vulnerability and often made them a source of risk to nearby buildings (Fig. 2).

On the west side of the Apennines there are some localities characterized by reconstructed or reinforced buildings following the 1979 and 1997-98 earthquakes (Norcia and UmbriaMarche events, respectively).

Historic buildings in square stone masonry with horizontal layers of bricks are less vul- compromised the structural behavior. Many buildings have been retrofitted by replacing wooden floors with hard and heavy slabs made of reinforced concrete and bricks

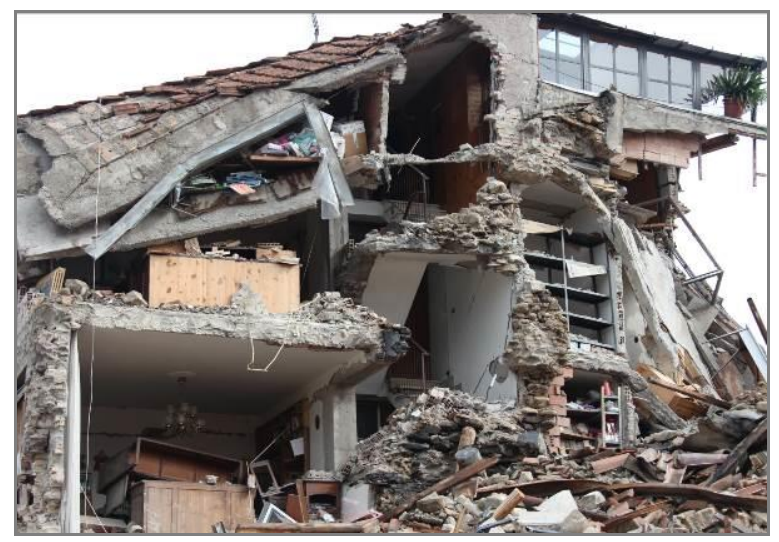

Figure 3: Amatrice: retrofit with (reinforced) concrete slab on old vertical walls without adequate reinforcement or proper connections between walls and floor.

nerable (class B) and were not heavily damaged for the most part, as well as reinforced concrete (RC) buildings built more recently (vulnerability class $C$ and D).

\section{MACROSEISMIC SURVEY: METHOD AND RESULTS}

Soon after the earthquake, the QUEST group (Quick Earthquake Survey Team) undertook the macroseismic survey with the aim of defining the damage scenario for civil protection purposes. During the first phase of the emergency, we carried out an expeditious investigation in cooperation with the Civil Protection Department by adopting the MercalliCancani-Sieberg (MCS) macroseismic scale (Galli et al., 2016). In order to properly take into account the variability of the damage effects due to building vulnerability, and hence the associated uncertainties in the intensity as- 
sessment, the survey continued with detailed inspections of the most damaged areas by using the EMS. The investigation involved a working group with specific field experience in applying the EMS in cases of recent, damaging earthquakes (experts from the INGV departments of Rome, Bologna, Catania, Milano and Pisa), who operated according to a procedure that has been implemented, step by step, since the 1997-98 Umbria-Marche seismic sequence (Camassi et al., 2008) till the 2009 L'Aquila and 2012 Emilia earthquakes (Tertulliani et al., 2011, 2012; Azzaro et al. 2011). A remote support was operated from the head office in Rome to coordinate the field teams.

The EMS survey also included smaller settlements that had not been considered previously and was extended to investigate the transition area from moderate damage to slightnegligible one, i.e. 5-6 degrees EMS, where the survey was stopped. In other words, areas not affected by damage (only felt reports) are not considered in the present macroseismic investigation. In total, we have inspected more than 150 localities, hamlets included. For each of them the focus was on establishing the number of buildings, their typology, the elements of specific vulnerability, grade of damage and percentage of damaged edifices and, i.e. the diagnostics of the EMS. All the information was reported in common forms routinely used by QUEST, which were later used to assess intensity. It should be stressed that problematic sites were surveyed up to three times by different teams in order to reduce the subjectivity of evaluation. The final number of localities for which it has been possible to assign an intensity value according to the EMS guidelines was 143 , referred to 40 municipalities.
The distribution of the macroseismic effects estimated by the EMS is shown in Figure 4 and the localities inventory is given in the Appendix. In general, the distribution of the effects in the near-field (I $\geq 8$ EMS) shows a pattern elongated in the NNW-SSE direction, with a strong attenuation of intensities southward (province of L'Aquila). On the contrary, slight but diffuse damage extends northward (provinces of Fermo and Macerata). Lastly, a possible effect of aggravation of damage due to the $\mathrm{M}_{\mathrm{w}} 5.4$ aftershock is observed at San Pellegrino di Norcia.

A short overview of damage scenarios and related EMS intensities in some key localities, is hereinafter reported.

\section{Degree 10}

Some localities in the epicentral area suffered the almost total destruction of low qualityhigh vulnerability buildings (class A) and of many masonry buildings (class B). Exemplary is the situation of the historical centre of Amatrice, where also some RC buildings (class $\mathrm{C}$ ) collapsed (Fig. 5). A special case is represented by the settlement of Pescara del Tronto, built on debris cone deposits of a landslide that has been reactivated during the earthquake.

\section{Degree 9}

Many hamlets of the territory north of Amatrice suffered very heavy damage - total or near total collapse of class A buildings.

\section{Degree 8}

Accumoli, Arquata del Tronto and other localities over an area trending broadly N-S for 15 $\mathrm{km}$, were affected by severe damage and some collapses of class A buildings. 


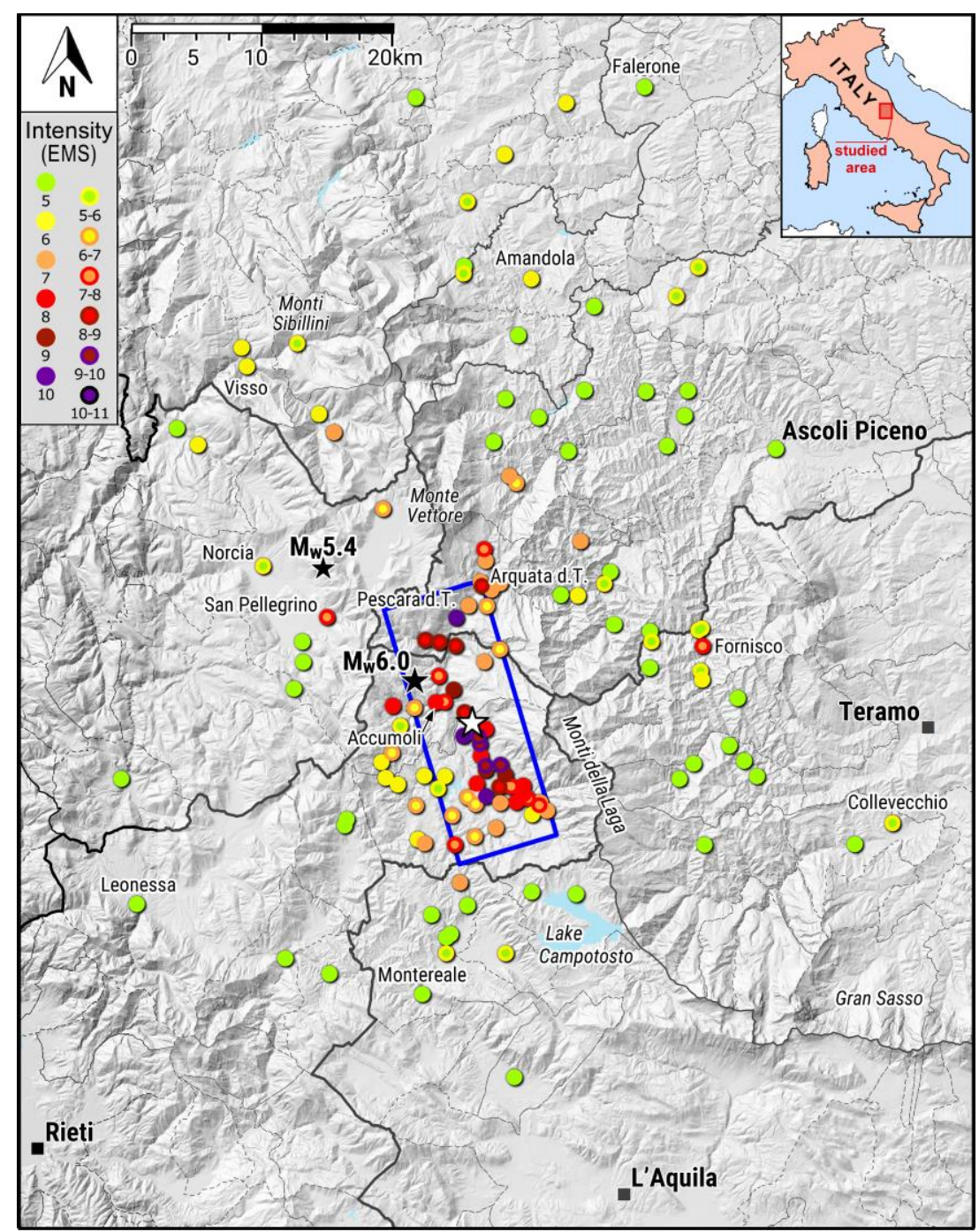

Figure 4: EMS intensity map of the August 24, 2016 Amatrice earthquake. Black stars, instrumental epicenters; white star, macroseimic epicenter calculated by using the Boxer method (Gasperini et al., 2010): lat. 42.679, long. 13.280; the magnitude obtained by intensity data is $M_{w} 6.3$.

Degree 7

Moderate damage and a few partial collapses of class A buildings occurred in an area extending for $30 \mathrm{~km}$ along the same N-S strike. Worthy of note is the case of Fornisco, within the slight damage area to the east of the epicentre.
Degree 6

The distribution of slight damage (i.e. cracks in the plaster, partial collapse of chimneys) is particular. A substantial number of localities lie west of Amatrice, just 4-6 km far from the area of degree 9 or 10. Another group is located in the northern part of the surveyed area, looking like an anomaly inside the degree 5 zone. 

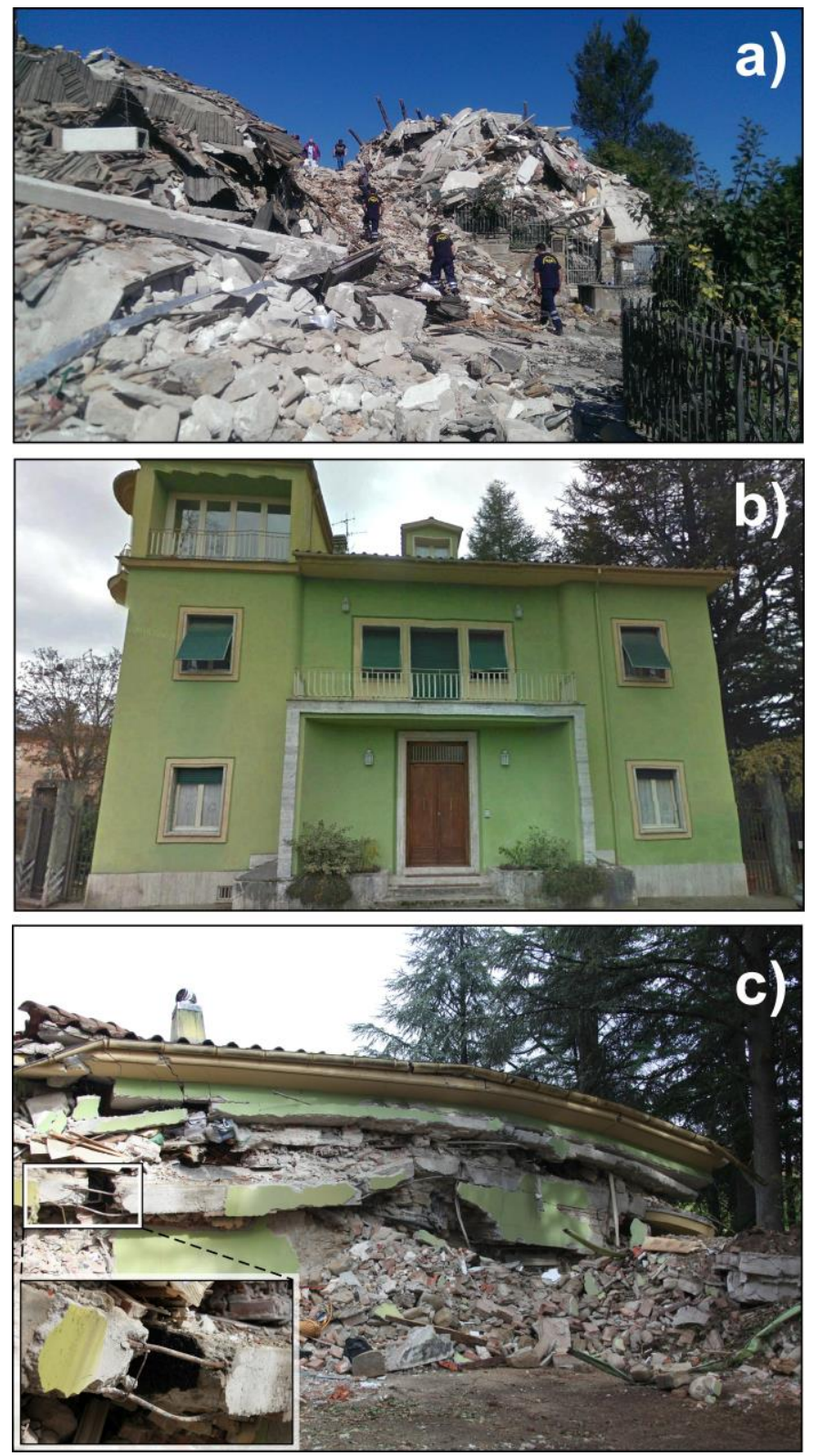

Figure 5: Example of damage to RC buildings: a) Saletta (Amatrice), collapse of individual residential houses; $b$ ) Amatrice: a two-storey building before the 24 August 2016 earthquake (photo by Google ${ }^{\mathrm{TM}}$ Street View, 2016), and c) the resulting sandwich collapse. Inset: detail of the smooth reinforcing bars.

Degree 5

As reported in the EMS guidelines (Grünthal, 1998), we also considered localities where occasional, very slight damage (i.e. hair-line cracks in the plaster) affected a few buildings of vulnerability class A and B. Due to the difficulties of observing these negligible effects (often visible only inside the edifices) as well 
as the extension of the involved area, the inventory of localities is incomplete.

\section{DISCUSSION AND CONCLUSIONS}

From the macroseismic point of view, the epicentral area of the 24 August 2016 earthquake extends between Amatrice and Arquata del Tronto. Here most of the ancient vulnerable building stock (class A) collapsed while the remaining part of masonry structures suffered from heavy (e.g. large diagonal cracks in the walls) to very heavy damage (serious failure of walls). RC buildings (class C) generally suffered heavy non-structural damage, although the failure of infill panels is rather striking; some collapses also occurred (e.g. in Amatrice). However, the high concentration of damage in specific zones depends not only on purely engineering factors (poor materials, slipshod workmanship, state of repair and maintenance), but also on site effects (geotechnical properties of terrains, presence of steep slopes and ridges). In some cases (e.g. Comunanza, Amandola) the heterogeneity of building vulnerability determined a striking difference in damage severity between historical centres and recent suburbs.

Furthermore, it should be stressed that the effects of past seismicity in the localities of the epicentral area were not properly considered to improve building vulnerability over time. The lack of memory of relevant seismic impact can be ascribed to the long time elapsed since the last local event in 1639, with the only exception of Norcia that was struck in 1979. On the other hand, some recent repairs produced an unexpected but recurrent type of damage (i.e. the collapse of old stonewalls under the weight of heavy RC slabs). This situation deserves further analyses if we consider that seismic rules have been mandatory since 1915 for Amatrice, 1927 for Accumoli and only 1984 for Arquata del Tronto.

\section{ACKNOWLEDGMENTS}

Ina Cecić is thanked for her suggestions that improved the manuscript.

\section{APPENDIX}

List of the investigated localities and EMS intensities assessed for the 24 August 2016 earthquake ( $M_{w}$ 6.0).

\section{REFERENCES}

Azzaro, R., Barbano, M.S., D'Amico, S., Tuvè, T., Scarfì, L. and Mostaccio, A. (2011). The L'Aquila 2009 earthquake: an application of the European Macroseismic Scale to the damage survey in the epicentral area. Boll. Geof. Teor. Appl., 52:561-581.

Camassi, R., Azzaro, R. and Tertulliani, A. (2008). Macroseismology: the lessons learnt from the 1997/1998 Colfiorito seismic sequence. Ann. Geophys., 51:331-342.

Galli, P., Peronace, E. and Tertulliani, A. (eds.) (2016). Rapporto sugli effetti del terremoto del 24 agosto 2016 di Amatrice in scala MCS. Roma, rapporto congiunto DPC, CNR-IGAG, INGV, 15 pp., doi: 10.5281/zenodo.161323. http://quest.ingv.it/index.php/rilievimacrosismici.

Gasperini, P., Vannucci, G., Tripone, D. and Boschi, E. (2010). The location and sizing of historical earthquakes using the attenuation of macroseismic intensity with distance. Bull. Seism. Soc. Am., 100:2035-2066.

Grünthal, G. (ed.) (1998). European Macroseismic Scale 1998 (EMS-98). Cahiers du Centre Européen de Géodynamique et de Séismolo- 
gie, 15, Luxembourg, 99 pp., Mese, S., Ercolani, E., Graziani, L., Leschiutta, http://www.ecgs.lu/cahiers-bleus/. I., Rossi, A. and Vecchi, M. (2011). An application of EMS98 in a medium-sized city: the case of L'Aquila (Central Italy) after the April 6, 2009 Mw 6.3 earthquake. Bull. Earthquake Eng., 9:67-80.

Tertulliani, A., Arcoraci, L., Berardi, M., Bernardini, F., Brizuela, B., Castellano, C., Del Mese, S., Ercolani, E., Graziani, L., Maramai, A., Rossi, A., Sbarra, M. and Vecchi, M. (2012). The Emilia 2012 sequence: a macroseismic survey. Ann. Geophys., "The Emilia (northern Italy) seismic sequence of MayJune, 2012: preliminary data and results", Anzidei, M., Maramai, A. and Montone, P. (eds), 55:4, 679-687; doi 10.4401/ag-6140. 